NOTE

\title{
Enumeration of bacteria which cleave or demethylate dimethylsulfoniopropionate in the Caribbean Sea
}

\author{
Pieter T. Visscher, Mara R. Diaz, Barrie F. Taylor \\ Division of Marine and Atmospheric Chemistry, Rosenstiel School of Marine and Atmospheric Science, 4600 Rickenbacker Causeway, \\ Miami, Florida 33149-1098, USA
}

\begin{abstract}
Populations of dimethylsulfoniopropionate (DMSP) degrading bacteria were enumerated in Caribbean Sea waters using Most Probable Number (MPN) methodology. DMSP and 3-methiolpropionate (MMPA), an intermediate in the demethylation pathway of DMSP degradation, were used as enrichment substrates. Two metabolically distinct populations were obtained: DMSP cleavers, which produced dimethyl sulfide (DMS) from DMSP, and demethylators of DMSP, which produced 3-mercaptopropionate (MPA) and/or methanethiol (MSH) from DMSP or MMPA. Demethylating populations were distinct from DMS producers and formed 5 to $66 \%$ of total DMSP degraders. DMSP utilizers comprized about $10 \%$ of the total bacteria (MPNs on glucose-acetate) indicating the potential of DMSP as a carbon source for bacteria in the euphotic zone
\end{abstract}

Dimethylsulfoniopropionate (DMSP) is synthesized by certain phytoplankton, most notably by some species of dinoflagellates and coccolithophores in which it functions as an osmolyte (Keller et al. 1989). There is interest in the environmental fate of DMSP because it is the principal precursor of dimethyl sulfide (DMS). Quantitatively, DMS is the most important volatile sulfur compound entering the marine atmosphere (Andreae 1990). Evidence from culture studies suggest that DMSP might be released from phytoplankton into seawater by a variety of mechanisms (Dacey \& Wakeham 1986) where it is enzymatically cleaved to DMS and acrylate by bacteria (Dacey \& Blough 1987, Kiene 1992).

Comparisons of the kinetics of DMSP and DMS turnover in surface oceanic and estuarine waters have indicated alternative fates for DMSP other than DMS production (Kiene \& Service 1991, Kiene 1992). Indeed, alternative catabolic routes for DMSP are known. In anoxic coastal sediments DMSP was demethylated to 3-methiolpropionate (MMPA) and thence to 3-mercaptopropionate (MPA) (Fig. 1) (Kiene \& Taylor 1988a, b). A marine bacterium, isolated from a culture of the coccolithophore Emiliania huxleyi, aerobically demethylated DMSP to MMPA, which was mainly demethiolated to yield methanethiol but also demethylated MMPA to MPA (Fig, 1) (Taylor \& Gilchrist 1991).

In the present study, we used DMSP and MMPA as selective growth substrates in Most Probable Number

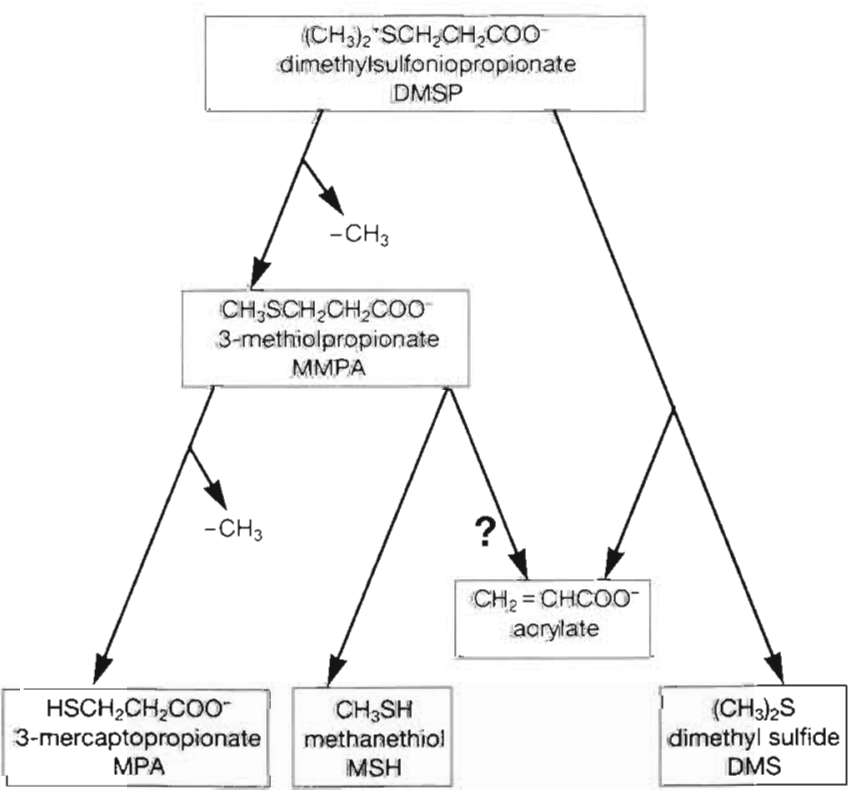

Fig. 1. Pathways of DMSP metabolism in the marine environment. Shaded boxes indicate products measured in the present study 
(MPN) enumerations. We found evidence for 2 distinct bacterial populations involved in DMSP degradation in oceanic waters based on the detection of key metabolic intermediates from either DMSP or MMPA.

Materials and methods. MPN incubations were carried out with samples collected during a cruise aboard the RV 'Columbus Iselin' in the Caribbean Sea. Samples were taken west of Montserrat, Leeward Islands $\left(16^{\circ} 45^{\prime} \mathrm{N}, 62^{\circ} 30^{\prime} \mathrm{W}_{i} \mathrm{Stn} 1\right)$ and southeast of Puerto Rico $\left(18^{\circ} 66^{\prime} \mathrm{N}, 65^{\circ} 45^{\prime} \mathrm{W}_{i} \operatorname{Stn} 2\right)$. Surface samples were collected by bucket (acid and ethanol rinsed) and samples from the chlorophyll (chl a) maximum and below were taken during CTD hydrocast with Niskin bottles.

The MPN medium consisted of a mixture $(1: 1 \mathrm{v} / \mathrm{v})$ of filtered and autoclaved aged-seawater and a carbonate-buffered mineral medium (Visscher et al. 1991), $3 \mathrm{ml}$ of which was dispensed in $6 \mathrm{ml}$ test tubes, which were closed off by an over-sized cap, allowing gas exchange. Substrates tested were DMSP, MMPA, both at a final concentration of $360 \mu \mathrm{M}$, and glucose plus acetate added to a final concentration of $180 \mu \mathrm{M}$ each. Incubations ( 3 replicates per treatment) were carried out in the dark and the tubes were vortexed 3 times per day to replenish the medium with oxygen. Controls either contained no substrate and an inoculum, or no inoculum and substrate.

Heterotrophic growth on glucose plus acetate was checked by turbidity, while growth on sulfur compounds was followed by production of the volatile gases DMS, MSH and dimethyldisulfide (DMDS). A headspace sample was removed aseptically from each tube and analyzed for these gases with a Shimadzu GC-Mini 2 gas chromatograph with flame ionization detector and Carbopak BHT column (Supelco, Bellefonte, PA, USA). The column temperature was $100^{\circ} \mathrm{C}$ and carrier gas flow was $60 \mathrm{ml} \mathrm{min}^{-1}$. Detection limits were $3 \mathrm{nmol}(1 \mu \mathrm{M})$ for DMS and $\mathrm{MSH}$ and $30 \mathrm{nmol}(10 \mu \mathrm{M})$ for DMDS. Production of the gases was followed over time by sampling at 4 to $24 \mathrm{~h}$ intervals. Positive tubes were removed to avoid carry-over of gases to neighbouring tubes, and kept for microscopic observation and consecutive transfer to fresh medium. The final population size was determined after 14 to 21 d of incubation according to De Man (1975). The production of MPA was measured in the laboratory in subsamples of all of the tubes with either DMSP or MMPA media after reduction of its chemical oxidation product, 3,3'-dithiodipropionic acid. MPA was measured on reverse-phase HPLC after derivatizing to an isoindole (Mopper \& Delmas 1984, Kiene \& Taylor 1988b). Subsamples $(0.5 \mathrm{ml})$ were treated with $10 \mu \mathrm{l}$ tributylphosphine to cleave disulfide bonds prior to derivatizing (Mopper \& Taylor 1986). The detection limit for MPA was $0.2 \mathrm{nmol}(67 \mathrm{nM}$ ).
All tubes were examined microscopically and the highest positives for all treatments were transferred into fresh medium to confirm growth. Subsequently, samples of all tubes displaying growth at the highest dilutions on DMSP were incubated in a medium containing MMPA as the only substrate. Likewise, all of the positive MMPA tubes were transferred into DMSPcontaining medium. Growth was checked for $3 \mathrm{~d}$ by analyzing the headspace for MSH, DMS and DMDS, and the culture liquid for MPA after which the population was evaluated as described above.

Counts of bacterial cells in water samples were made using epifluorescence microscopy. Slides were prepared aboard ship, after fixing samples $(5 \mathrm{ml})$ in formaldehyde (final concentration $2 \% \mathrm{v} / \mathrm{v}$ ). Cells were stained with acridine orange (final concentration $0.01 \% \mathrm{v} / \mathrm{v}$ ), filtered onto $0.2 \mu \mathrm{m}$ black-stained Nuclepore filters (Hobbie et al. 1977), and kept refrigerated until counted.

DMSP was either obtained through Research Plus (Bayonne, NJ, USA), or synthesized (Chambers et al. 1987 ) and MMPA was obtained by alkaline hydrolysis of its methyl ester supplied by Aldrich (Milwaukee, WI, USA).

Results and discussion. In shipboard incubations, production of sulfur gases, which was used as a qualitative measure for bacterial metabolism, was observed within $24 \mathrm{~h}$ in lower dilutions $\left(10^{2}\right.$ to $\left.10^{3}\right)$ of all samples. Typically, the DMSP-cleaving population took 10 to $14 \mathrm{~d}$ to fully develop, while the MMPA utilizing population grew more slowly and peaked after 16 to $20 \mathrm{~d}$. The dominant volatile sulfur species detected from MMPA was MSH, while its oxidation product DMDS was only found at much lower concentrations. The glucose-acetate population fully developed within 4 to $6 \mathrm{~d}$.

At lower dilutions both DMSP and MMPA media supported growth, with DMS and MPA production in DMSP media contrasted by MSH and MPA production in MMPA media. The results indicate the presence of mixed populations carrying out cleavage, demethylation and demethiolation. At higher dilutions the products were either DMS or MSH and MPA indicating the dominance of either cleavers or demethylators/demethiolators.

The results of MPN (Table 1) showed no difference in population size between DMSP $\left(2.0 \times 10^{4}\right.$ to $2.0 \times$ $10^{5}$ cells $\left.\mathrm{ml}^{-1}\right)$ and MMPA utilizers $\left(4.0 \times 10^{2}\right.$ to $5.0 \times$ $10^{4}$ cells $\mathrm{ml}^{-1}$ ) based on $95 \%$ confidence intervals, although on average the DMS producers seemed to be present in slightly higher numbers. Except for MMPA incubations from Str 2 at the chl a maximum, the MPAproducing populations in DMSP and MMPA media were smaller than the DMS and MSH-producing population, respectively (Table 1 ). 
Table 1. Viable count (cells $\mathrm{ml}^{-1}$ ) of DMSP-utilizing bacteria and MMPA-utilizing bacteria (95\% confidence interval in parentheses). DMSP: dimethylsulfoniopropionate; MMPA: 3-methiolpropionate; DMS: dimethyl sulfide; MPA: 3-mercaptopropionate; nd: not determined

\begin{tabular}{|c|c|c|c|c|}
\hline Location & $\begin{array}{l}\text { DMS from } \\
\text { DMSP }\end{array}$ & $\begin{array}{l}\text { MPA from } \\
\text { DMSP }\end{array}$ & $\begin{array}{l}\text { MSH from } \\
\text { MMPA }\end{array}$ & $\begin{array}{l}\text { MPA from } \\
\text { MMPA }\end{array}$ \\
\hline \multicolumn{5}{|l|}{ Stn 1} \\
\hline Surface & $\begin{array}{c}4.0 \times 10^{4} \\
\left(2-21 \times 10^{4}\right)\end{array}$ & $\begin{array}{r}5.0 \times 10^{3} \\
\left(2-24 \times 10^{3}\right)\end{array}$ & $\begin{array}{r}2.1 \times 10^{3} \\
\left(0.8-6.4 \times 10^{3}\right)\end{array}$ & $\begin{array}{r}1.1 \times 10^{3} \\
\left(0.3-48 \times 10^{3}\right)\end{array}$ \\
\hline Chl a $\max (-80 \mathrm{~m})$ & $\begin{array}{c}2.0 \times 10^{4} \\
\left(1-14 \times 10^{4}\right)\end{array}$ & $\begin{array}{r}5.0 \times 10^{3} \\
\left(2-24 \times 10^{3}\right)\end{array}$ & $\begin{array}{c}5.0 \times 10^{4} \\
\left(2-24 \times 10^{4}\right)\end{array}$ & $\begin{array}{r}2.0 \times 10^{3} \\
\left(1-14 \times 10^{3}\right)\end{array}$ \\
\hline \multicolumn{5}{|l|}{$\operatorname{Stn} 2$} \\
\hline Chl a max $(-100 \mathrm{~m})$ & $\begin{array}{c}2.0 \times 10^{4} \\
\left(1-14 \times 10^{4}\right)\end{array}$ & $\begin{array}{c}4.0 \times 10^{2} \\
\left(2-21 \times 10^{2}\right)\end{array}$ & $\begin{array}{c}4.0 \times 10^{2} \\
\left(2-21 \times 10^{2}\right)\end{array}$ & $\begin{array}{r}1.1 \times 10^{3} \\
\left(0.3-48 \times 10^{3}\right)\end{array}$ \\
\hline Below chl a max $(-150 \mathrm{~m})$ & $\begin{array}{r}2.0 \times 10^{5} \\
\left(1-14 \times 10^{5}\right)\end{array}$ & $\begin{array}{r}4.0 \times 10^{3} \\
\left(2-21 \times 10^{3}\right)\end{array}$ & nd & nd \\
\hline
\end{tabular}

In the surface sample of Stn $1, \mathrm{ca} 6 \%$ of the total heterotrophic population used DMSP and/or MMPA (Fig. 2). At the chl a maximum, this was $10 \%$ for both stations, whereas at Stn 2, below the chl a maximum, the population of DMSP and/or MMPA utilizers slightly exceeded the glucose-acetate population. Total counts with epifluorescence showed that 20 to $50 \%$ of the total bacterial population was retrieved with the MPN incubation containing glucose plus acetate (Fig. 2). The results suggest that DMSP may be an important carbon source for bacteria in seawater, as previously suggested for sediments (Kiene \& Taylor $1988 \mathrm{~b})$. However, further quantitative studies will need to be done to address this question.

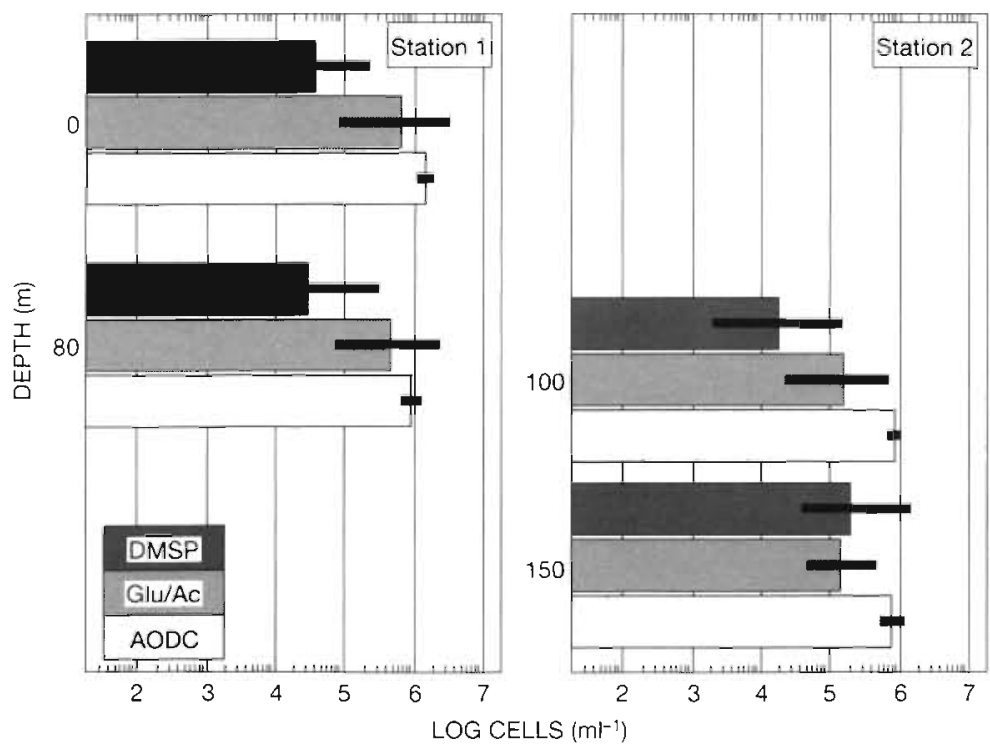

Fig. 2. Depth profiles of microbial populations using DMSP, glucose + acetate (Glu/Ac; error bars indicate the $95 \%$ confidence interval) and Acridine Orange Direct Counts (AODC; error bars indicate standard deviation). The chlorophyll a maximum was at 80 and $100 \mathrm{~m}$ depth at Stns $1 \& 2$, respectively
When the positive cultures from DMSP media which produced only DMS were transferred to MMPA medium, no thiol production or growth was detected. On the other hand, when populations in which originally both DMS and MPA were detected (so-called double positives), were transferred to an MMPA-medium, none produced DMS or MSH but nearly all produced MPA. Exceptions were one of the highest double positives of Stn 1, at the chl a maximum, and one of the highest double positives of Stn 2, below the chl a maximum, which showed no growth on MMPA or production of MPA from MMPA (20 and $25 \%$ of the original total populations, respectively).

Conversely, when MMPA utilizers were incubated in the presence of DMSP, all except two of the highest positive tubes of Stn 1, at the chl a maximum, used DMSP and produced MPA and/or MSH but not DMS $(40 \%$ of the total population of Stn 1 , at the chl a maxium, did not use DMSP). Production of MPA by populations originally enumerated on MMPA occurred on the average within 24 to $48 \mathrm{~h}$ as opposed to $72 \mathrm{~h}$ by populations obtained on DMSP.

Although the cleavage pathway is conspicuous, because of the importance of DMS in atmospheric chemistry and climate, a major fraction of the DMSP in the water column is probably degraded by other routes (Kiene 1990, 1992, Kiene \& Service 1991). In estuarine waters less than $30 \%$ of the DMSP was converted to DMS (Kiene \& Service 1991). With sea water samples from the Sargasso Sea, near Stn 2 of our study, Kiene (1992) found less than $25 \%$ of added DMSP was retrieved as DMS, even when DMS consumption was inhibited by $\mathrm{CHCl}_{3}$. 
These findings indicated alternative pathways of DMSP degradation in oxic environments and our findings provide direct evidence for the presence of bacteria involved in demethylation and/or demethiolation transformations (Fig. 1).

In this study, we enumerated viable populations on DMSP and on MMPA. The latter is an intermediate in the demethylation and demethiolation routes (Fig. 1). Our data show that with the same inoculum, populations using all 3 pathways were present. Transfer of populations which only cleave DMSP to DMS (highest positives tubes) to medium containing MMPA showed that these consisted of DMS-producers only. Similarly, all but 2 populations obtained on MMPA demethylated and/or demethiolated DMSP, while no cleavage was detected. Aerobic demethylation of DMSP has not previously been documented in any environment. Our data confirm the idea that DMSP demethylation and MMPA catabolism are linked and carried out by the same microbial population, which is distinct from that responsible for DMSP cleavage (Taylor \& Gilchrist 1991). MMPA degradation with methanethiol formation needs investigation under in situ conditions since methanethiol is not usually detected in surface oceanic waters. As previously suggested (Taylor \& Gilchrist 1991) the aerobic demethiolation of MMPA may dominate at elevated MMPA concentrations. MMPA levels are probably low in natural environments, certainly lower than used in the MPN determinations, and demethylation may dominate over demethiolation. The occurrence of organisms that preferentially demethylate rather than demethiolate MMPA is indicated by the enrichments which produced DMS and MPA from DMSP but on transfer to MMPA gave MPA but not methanethiol.

The composition of the medium, especially the growth substrate, gives the MPN method its selectivity, and as noted above, it would be preferable to use levels that are closer to the natural situation 10 to $100 \mathrm{nM}$ ). In spite of its limitations the MPN results allow an estimate that the total DMSP-consuming population was composed of 33 to $95 \%$ cleavers and 5 to $66 \%$ demethylators/demethiolators. These percentages indicate the populations recovered and do not indicate in situ activities. The contribution of each metabolic group depends on population size, biochemical and physiological characteristics, and environmental factors such as fluctuations in DMSP levels. Our data emphasizes the need for studies of environmental turnover rates for key intermediates and the physiology of pure cultures to understand the fate of DMSP in marine regions.

This note was presented by J. Fuhrman, Los Angeles, California, USA
Acknowledgements. This study was supported by NSF grant OCE 9012157 P.T.V. acknowledges a grant from the Netherlands Organization for Scientific Research (NWO). We thank Edward J. Carpenter and Douglas G. Capone for providing space aboard the RV 'Columbus Iselin'; and Ron Kiene for a constructive review of the manscript.

\section{LITERATURE CITED}

Andreae, M. O. (1990). Ocean-atmosphere interactions in the global biogeochemical sulfur cycle. Mar. Chem. 30: 1-29

Chambers, S. T., Kunin, C. M., Miller, D., Hamada, A. (1987). Dimethylthetin can substitute for glycine betaine as an osmoprotectant molecule for Escherichia coli. J. Bacteriol. 169: $4845-4847$

Dacey, J. W. H., Blough, N. V. (1987). Hydroxide decomposition of dimethylsulfoniopropionate to form dimethylsulfide. J. geophys. Res. Lett. 14: 1246-1249

Dacey, J. W. H., Wakeham, S. G. (1986). Oceanic dimethyl sulfide: production during zooplankton grazing on phytoplankton. Science 233: 1314-1316

De Man, J. (1975). The probability of most probable numbers. Eur. J. appl. Microbiol. 1: 67-78

Hobbie, J. E., Daley, R. J., Jasper, S. (1977). Use of Nuclepore filters for counting bacteria by fluorescence microscopy. Appl. environ. Microbiol. 33: 1225-1228

Keller, M. D., Bellows, W. K., Guillard, R. R. L. (1989). Dimethyl sulfide production in marine phytoplankton. In: Saltzman, E. S., Cooper, W. J. (eds.) Biogenic sulfur in the environment. American Chemical Society, Washington, DC, p. 167-182

Kiene, R. P. (1990). Dimethyl sulfide production from dimethylsulfoniopropionate in coastal seawater samples and bacterial cultures. Appl. environ. Microbiol. 56: 3292-3297

Kiene, R. P. (1992). Dynamics of dimethyl sulfide and dimethylsulfoniopropionate in oceanic water samples. Mar. Chem. $37: 29-52$

Kiene, R. P., Service, S. K. (1991). Decomposition of dissolved DMSP and DMS in estuarine water: dependence on temperature and substrate concentration. Mar. Ecol. Prog. Ser. 76: 1-11

Kiene, R. P., Taylor, B. F. (1988a). Biotransformations of organosulphur compounds in sediments via 3 -mercaptopropionate. Nature 332: 148-150

Kiene, R. P., Taylor, B. F. (1988b). Demethylation of dimethylsulfoniopropionate and production of thiols in anoxic marine sediments. Appl. environ. Microbiol. 54: 2208-2212

Mopper, K., Delmas, D. (1984). Trace determination of biological thiols by liquid chromatography and precolumn fluorometric labeling with o-phthalaldehyde. Anal. Chem. 56: $2557-2560$

Mopper, K., Taylor, B. F. (1986). Biogeochemical cycling of sulfur. Thiols in coastal marine sediments. In: Sohn, M. L. (ed.) Organic marine chemistry, American Chemical Society, Washington, DC, p. 324-339

Taylor, B. F., Gilchrist, D. C. (1991). New routes for aerobic biodegradation of dimethylsulfoniopropionate. Appl. environ. Microbiol. 57: 3581-3584

Visscher, P. T., Quist, P., van Gemerden, H. (1991). Methylated sulfur compounds in microbial mats: in situ concentrations and metabolism by a colorless sulfur bacterium. Appl environ. Microbiol. 57: 1758-1763

Manuscript first received: May 20, 1992

Revised version accepted: October 16, 1992 